\title{
HETEROARYLAMINATION AND HETEROARYLSULFIDATION OF 2-CHLORO-1-AZAAZULENES
}

\section{Eiko Yoshioka, ${ }^{1}$ Kazuya Koizumi, ${ }^{1}$ Shinya Yamazaki, ${ }^{1}$ Hiroyuki Fujii, ${ }^{2}$ and Noritaka $\mathrm{Abe}^{1_{*}}$}

\author{
${ }^{1}$ Graduate School of Medicine, and Department of Biology and Chemistry, \\ Faculty of Science, Yamaguchi University, Yoshida, Yamaguchi 753-8512, Japan \\ ${ }^{2}$ Science Research Center, Yamaguchi University, Yamaguchi 753-8512, Japan
}

\begin{abstract}
Heteroarylamination and heteroarylsulfidation of 2-chloro-1-azaazulenes (1) were investigated. Palladium catalyzed coupling of 2-amino-1-azaazulenes (2) with 1 underwent to give bis(1-azaazulen-2-yl)amine derivatives in good yields, but the reaction of 2-mercapto-1-azaazulenes (4) with $\mathbf{1}$ did not give good results in the same conditions. The reaction of $\mathbf{4}$ with $\mathbf{1}$ under basic conditions gave bis(1-azaazulen-2-yl) sulfide derivatives in good yields. Heteroarylamino-substitution was proceeded on the reaction of 4-amino-3-mercapto-4H-1,2,4-triazoles (6) with $\mathbf{1}$ in $\mathrm{BuOH}$ under reflux, whereas heteroarylsulfido-substitution was proceeded on the reaction of $\mathbf{6}$ with $\mathbf{1}$ in the presence of $\mathrm{NaH}$ in dioxane.
\end{abstract}

The chemistry of azaazulenes ${ }^{1}$ is of interest for their physiological properties ${ }^{2,3}$ as well as physical and chemical properties. Aryl amines have a potential functionality in pharmaceutical drug candidates, ${ }^{4-8}$ therefore Pd-catalyzed amination of aryl halides has attracted attention. ${ }^{9}$ Recently, we reported that heteroarylaminatition of ethyl 2-chloro-1-azaazulene-3-carboxylate proceeded well by Pd-catalyzed amination. $^{10}$ In the extension of the chemistry, we examined the reaction of 2-chloro-1-azaazulenes with 2-amino-1-azaazulenes, mercapto-1-azaazulenes, and 4-amino-3-mercapto-4H-1,2,4-triazoles.

Treatment of 2-chloro-1-azaazulene (1a) with 2-amino-1-azaazulene (2a) in the presence of $\mathrm{Pd}_{2}(\mathrm{dba})_{3}$, Xantphos, and $\mathrm{Cs}_{2} \mathrm{CO}_{3}$ in dioxane under reflux for $4 \mathrm{~h}$ gave bis(1-azaazulen-2-yl)amine (3aa) in 39\% yield. The ${ }^{1} \mathrm{H}$ NMR spectrum of 3aa was symmetrical and the ${ }^{13} \mathrm{C}$ NMR spectrum showed 9 signals; 
this showed that heteroarylamination occurred at amino group at C-2, and not at $\mathrm{N}-1$ of 1-azaazulene nuclei. Similar treatment of $\mathbf{1 b}, \mathbf{1 c}$, and $\mathbf{1 d}$ with $\mathbf{2 a}$ and $\mathbf{2 b}$ gave 3ba (70\%), 3ca (63\%), and 3db (43\%), respectively. Although the yields were slightly low as the case, the usefulness of Pd-catalyzed heteroarylamination was certified for the synthesis of bis(1-azaazulen-2-yl)amine derivatives.

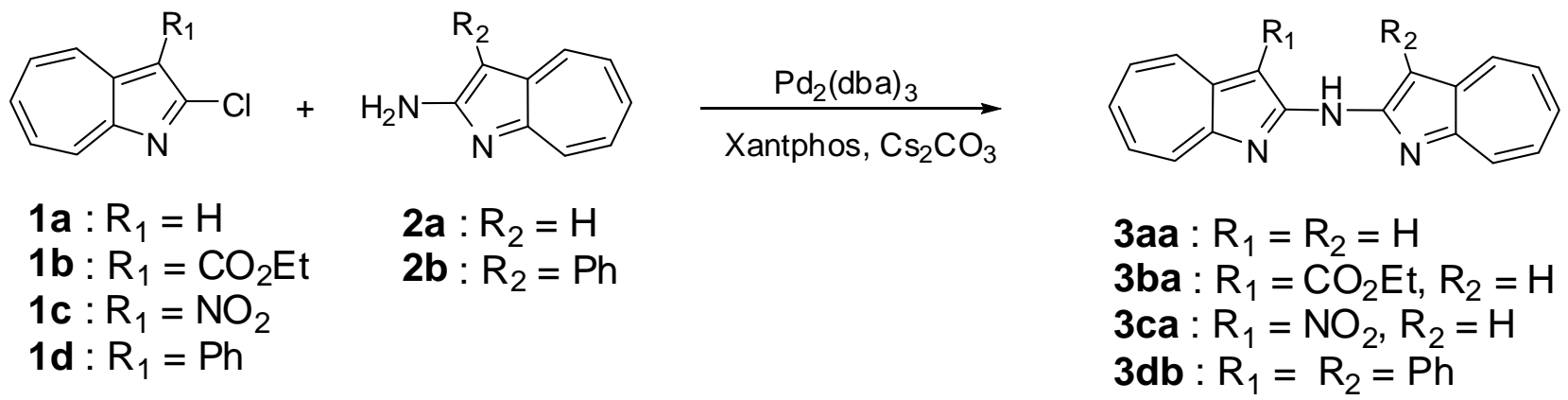

\section{Scheme 1}

Next, we investigated the reaction of 2-chloro-1-azaazulenes with 2-mercapto-1-azaazulenes. Treatment of $\mathbf{1 b}$ with $\mathbf{4 a}$ in the presence of $\mathrm{Pd}_{2}(\mathrm{dba})_{3}$, Xantphos, and $\mathrm{Cs}_{2} \mathrm{CO}_{3}$ in dry 1,4-dioxane for $24 \mathrm{~h}$ under reflux gave $\mathbf{5 b a}$ in $50 \%$ yield. In a similar manner, the reaction of $\mathbf{1 c}$ with $\mathbf{4 a}$ gave $\mathbf{5 c a}(38 \%)$. Although the coupling products were obtained, the yields were not so well, and it is considered that the occurrence of $S_{N} A r$ reaction was within the bounds of possibility, because it is known that $S_{N} A r$ reaction occurs in the reaction of 2-chloro-1-azaazulenes with good nucleophile, such as alkoxide and sulfoxide. ${ }^{1}$ In addition, the possibility of poisoning of Pd-catalyst by S-atom would be considered. Therefore, we performed the reaction of $\mathbf{1 a}$ with $\mathbf{4 a}$ in the presence of $\mathrm{NaH}$ in dry 1,4-dioxane for $4 \mathrm{~h}$ under reflux, and 5aa was obtained in $88 \%$ yield. In a similar manner, the reaction of $\mathbf{1 b}$ and $\mathbf{1 c}$ with $\mathbf{4 a}$ and $\mathbf{4 b}$ gave $5 \mathbf{b a}$ (71\%), 5ca (80\%), and 5cb (85\%), respectively. Thus, the reaction of 2-mercapto-1-azaazulenes in the presence of base was preferred to undergo the $S_{N} A r$ reaction on S-atom and gave bis(1-azaazulen-2-yl) sulfides, and heteroarylamination on N-1 atom of $\mathbf{4}$ did not proceed.

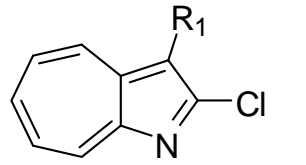

$1 \mathrm{a}: \mathrm{R}_{1}=\mathrm{H}$

1b : $\mathrm{R}_{1}=\mathrm{CO}_{2} \mathrm{Et}$

1c : $\mathrm{R}_{1}=\mathrm{NO}_{2}$
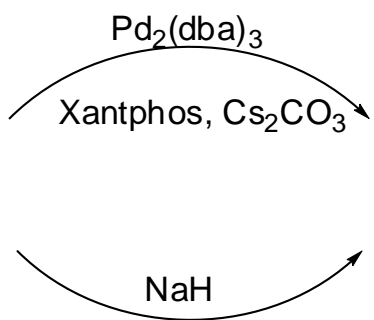

in dioxane

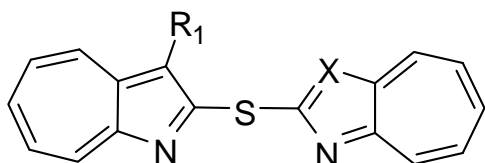

5aa: $\mathrm{R}_{1}=\mathrm{H}, \mathrm{X}=\mathrm{CH}$ 5ba: $\mathrm{R}_{1}=\mathrm{CO}_{2} \mathrm{Et}, \mathrm{X}=\mathrm{CH}$ 5ca: $\mathrm{R}_{1}=\mathrm{NO}_{2}, \mathrm{X}=\mathrm{CH}$ 5cb : $\mathrm{R}_{1}=\mathrm{NO}_{2}, \mathrm{X}=\mathrm{N}$

Scheme 2

Next, for comparison of the reactivity of $\mathrm{SH}$ and $\mathrm{NH}_{2}$ groups in the reaction, we adopted 4-amino-3-mercapto-4H-1,2,4-triazoles (6) as reagents, which have $\mathrm{SH}$ and $\mathrm{NH}_{2}$ groups in a molecule. In addition, the mercapto group in $\mathbf{6}$ could have thione-form, therefore it is considered that the mercapto 
group of $\mathbf{6}$ would be a poor nucleophile. Thus, we treated $\mathbf{1 b}$ with $\mathbf{6 a}$ in the presence of $\operatorname{Pd}_{2}\left(\mathrm{dba}_{3}\right.$, Xantphos, and $\mathrm{Cs}_{2} \mathrm{CO}_{3}$ in dioxane at $120{ }^{\circ} \mathrm{C}$ for $24 \mathrm{~h}$, but the reaction showed complex feature and no distinct product was isolated. Then we treated $\mathbf{1 b}$ with $\mathbf{6 a}$ in $\mathrm{BuOH}$ under reflux for 30 min. Interestingly, the $\mathrm{S}_{\mathrm{N}} \mathrm{Ar}$ reaction by the $\mathrm{NH}_{2}$ group occurred and 7a was obtained in 92\% yield. In the ${ }^{1} \mathrm{H}$ NMR spectrum of 7a, two singlet signals owing to $\mathrm{NH}$ and SH appeared at $\delta 10.58$ and 13.99 . In the IR spectrum of 7a, an NH signal appeared at $3292 \mathrm{~cm}^{-1}$. From the results, we assigned the structure. In a similar manner, the reaction of $\mathbf{1 b}$ with $\mathbf{6 b}$ and $\mathbf{6 c}$ gave $\mathbf{7 b}(98 \%)$ and $\mathbf{7 c}(43 \%)$, respectively.<smiles>CCOC(=O)c1c2cccccc-2nc1Cl</smiles>

$1 b$<smiles>[R]c1nnc(S)n1N</smiles>

$6 \mathbf{a}: \mathrm{R}=\mathrm{H}$ 6b: $\mathrm{R}=\mathrm{CH}_{3}$ 6c $: \mathrm{R}=\mathrm{CF}_{3}$

B) $\mathrm{K}_{2} \mathrm{CO}_{3} / 18$-crown-6 in dioxane<smiles>[R]c1nnc(S)n1Nc1nc2cccccc-2c1C(=O)OCC</smiles>

$7 a: R=H$ $7 b: \mathrm{R}=\mathrm{CH}_{3}$ 7c $: \mathrm{R}=\mathrm{CF}_{3}$

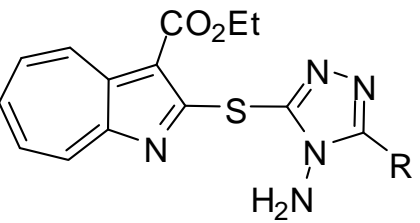

$8 a: R=H$

$8 \mathbf{b}: \mathrm{R}=\mathrm{CH}_{3}$

$8 \mathrm{c}: \mathrm{R}=\mathrm{CF}_{3}$

\section{Scheme 3}

On the contrary, when $\mathbf{1 b}$ was treated with $\mathbf{6 a}$ in the presence of $\mathrm{NaH}$ in dry 1,4-dioxane for $10 \mathrm{~h}$ under reflux, the $S_{N} A r$ reaction by the sulfido group occurred and 8 a was obtained in $91 \%$ yield. In the ${ }^{1} \mathrm{H}$ NMR spectrum of $\mathbf{8 a}$, a $2 \mathrm{H}$ singlet signal owing to $\mathrm{NH}_{2}$ appeared at $\delta 5.45$, and in its IR spectrum, signals owing to $\mathrm{NH}_{2}$ appeared at 3251 and $3156 \mathrm{~cm}^{-1}$. From the results, we assigned the structure. Similar reaction of $\mathbf{1 b}$ with $\mathbf{6 b}$ gave $\mathbf{8 b}$ in $85 \%$ yield, but the reaction of $\mathbf{1 b}$ with $\mathbf{6 c}$ gave no good result. It is observed that $\mathbf{6 c}$ decomposed by the treatment with $\mathrm{NaH}$, therefore use of more weak base would be required. So we examined the reaction of $\mathbf{1 b}$ with $\mathbf{6 c}$ in the presence of $\mathrm{K}_{2} \mathrm{CO}_{3}$ and 18-crown-6 in dry dioxane under refluxed for $1 \mathrm{~h}$, and obtained $\mathbf{8 c}$ in $92 \%$ yield. In a similar manner, the reaction of $\mathbf{1 b}$ with $\mathbf{6 a}$ and $\mathbf{6 b}$ gave $\mathbf{8 b}(92 \%)$ and $\mathbf{8 c}(86 \%)$, respectively.

Thus, each heteroarylamination and heteroarylsulfidation of 2-chloro-1-azaazulenes was achieved in the reaction of $\mathbf{1 b}$ with $\mathbf{6}$.

\section{EXPERIMENTAL}


Mps were measured using a Yanagimoto micro-melting apparatus and uncorrected. ${ }^{1} \mathrm{H}$ NMR spectra (including HH-COSY and CH-COSY NMR) were recorded on a Bruker AVANCE 400S (400 MHz) and ${ }^{13} \mathrm{C}$ NMR spectra were recorded on a Bruker AVANCE 400S (100.6 MHz) using $\mathrm{CDCl}_{3}$ as a solvent with tetramethylsilane as an internal standard unless otherwise stated; $J$ values are recorded in $\mathrm{Hz}$. IR spectra were recorded for $\mathrm{KBr}$ pellets on a Nicolet FT-IR AVATAR 370DTGS unless otherwise stated. Electronic spectra were recorded with JASCO V-570 spectrophotometer. Elemental analyses were taken with a Perkin Elmer 2400II. Kieselgel 60 was used for column chromatography.

\section{Reaction of 2-chloro-1-azaazulenes with 2-amino-1-azaazulenes}

Typical procedure: $\quad$ Under argon atmosphere, a mixture of 1a (0.046 g, $0.28 \mathrm{mmol}), 2 \mathrm{a}(0.030 \mathrm{~g}, 0.20$ mmol), Xantphos (0.008 g, $0.014 \mathrm{mmol}), \mathrm{Pd}_{2}(\mathrm{dba})_{3}(0.011 \mathrm{~g}, 0.012 \mathrm{mmol}), \mathrm{Cs}_{2} \mathrm{CO}_{3}(0.081 \mathrm{~g}, 0.240$ mmol) in dry 1,4-dioxane $(6 \mathrm{~mL})$ was refluxed for $4 \mathrm{~h}$, then water $(20 \mathrm{~mL})$ was added. The mixture was extracted with $\mathrm{CHCl}_{3}$. The extract was dried over $\mathrm{Na}_{2} \mathrm{SO}_{4}$, and evaporated. Chromatography of the residue with $\mathrm{CHCl}_{3}$-AcOEt (1 : 1) gave 3aa (0.022 g, 39\%).

In a similar manner, reaction of $\mathbf{1 b}, \mathbf{1 c}$, and $\mathbf{1 d}$ with $2 \mathbf{a}$ and $2 \mathbf{b}$ gave $3 \mathbf{b a}$ (70\%), 3ca (63\%), and 3db (43\%), respectively.

3aa : Red powders (from $\mathrm{CH}_{2} \mathrm{Cl}_{2}$-hexane), mp 197-199 ${ }^{\circ} \mathrm{C}$; ${ }^{1} \mathrm{H}$ NMR (DMSO-d $\left.d_{6}\right) \delta 7.54$ (2H, like t, $J$ 9.2, H-7,7’), 7.58 (2H, like t, J 9.1, H-5,5’), 7.64 (2H, s, H-3,3’), 7.66 (2H, like t, J 10.2, H-6,6'), 8.19 (2H, d, $J$ 9.6, H-4,4'), 8.32 (2H, dm, $J$ 10.7, H-8,8'), and 11.6 (1H, s, NH); ${ }^{13} \mathrm{C}$ NMR (DMSO-d 6 ) $\delta 103.1,129.0$, 129.5, 130.2, 130.3, 132.5, 147.2, 157.3, and 163.3; $v_{\max } / \mathrm{cm}^{-1} 3366(\mathrm{NH}) ; \lambda_{\max }\left(\mathrm{CH}_{2} \mathrm{Cl}_{2}\right) \mathrm{nm}(\log \varepsilon) 260$ (4.43), 282 (4.50), 339 (4.32), 411(4.34), 468 (4.11, sh), 485 (4.15), 514 (4.02, sh), and 570 (3.32, sh). Anal. Calcd for $\mathrm{C}_{18} \mathrm{H}_{13} \mathrm{~N}_{3}$ : C, 79.68; H, 4.83; N, 15.49. Found: C, 79.77; H, 4.82; N, 15.35 .

3ba : Orange needles (from $\mathrm{CH}_{2} \mathrm{Cl}_{2}$-hexane), mp 189-193 ${ }^{\circ} \mathrm{C} ;{ }^{1} \mathrm{H}$ NMR $\delta 1.55$ (3H, t, $J$ 7.1, Me), 4.57 (q, $J$ 7.1, $\mathrm{OCH}_{2}$ ), 7.54 (1H, ddd, $J$ 10.4, 9.5, and 1.2, H-5'), 7.60 (1H, ddd, $J$ 10.0, 9.7, and 1.2, H-7'), 7.66 (1H, ddd, $J$ 10.4, 9.7, and 0.9, H-6'), 7.69 (1H, td, $J$ 10.0, and 0.8, H-7), 7.79 (1H, ddd, $J$ 10.0, 9.8, and 0.3, H-6), 7.83 (1H, ddd, $J$ 9.9, 9.8, and 0.9, H-5), 8.33 (1H, dd, $J 9.5$ and 0.9, H-4'), 8.36 (1H, d, $J$ 10.0, H-8'), 8.37 (1H, s, H-3'), 8.51 (1H, dd, $J 10.0$ and 0.8, H-8), 9.15 (1H, d, J 9.9, H-4), and 10.71 (1H, s, $\mathrm{NH}) ;{ }^{13} \mathrm{C}$ NMR $\delta 14.7,60.6,100.2,103.9,129.2,130.0,130.6,131.5,132.1,132.8,133.2,133.3,133.5$, 134.4, 147.2, 148.4, 156.7, 160.6, 161.6, 163.5, and 165.4; $v_{\max } / \mathrm{cm}^{-1} 3280(\mathrm{NH})$ and $1660(\mathrm{C}=\mathrm{O}) ; \lambda_{\max }$ $\left(\mathrm{CH}_{2} \mathrm{Cl}_{2}\right) \mathrm{nm}$ (log $\left.\varepsilon\right) 276$ (4.58, sh), 288 (4.66), 315 (4.50, sh), 335 (4.47), 420 (4.58), 464 (3.97), and 484 (4.20). Anal. Calcd for $\mathrm{C}_{21} \mathrm{H}_{17} \mathrm{~N}_{3} \mathrm{O}_{2}$ : C, 73.45; H, 4.99; N, 12.24. Found: C, 73.55; H, 5.10; N, 12.03.

3ca : Orange powders (from AcOEt), mp 193-195 ${ }^{\circ} \mathrm{C}$; ${ }^{1} \mathrm{H}$ NMR $\delta 7.63$ (1H, dd, $J 10.4$ and 9.9, H-5'), 7.71 (1H, dd, $J 10.6$ and 10.4, H-7’), 7.74 (1H, dd, $J 10.6$ and 9.9, H-6'), 7.91 (1H, dd, $J 10.3$ and 9.9, H-5), 8.03 (1H, dd, J 9.9 and 9.8, H-7), 8.04 (1H, t, J 9.9, H-6), 8.44 (1H, d, J 10.4, H-4'), 8.45 (1H, d, J 
9.8, H-8), 9.47 (1H, d, $J$ 10.3, H-4), and 11.02 (1H, br s, NH); ${ }^{13} \mathrm{C}$ NMR $\delta 104.4,119.8,129.5,130.3$, 132.3, 132.6, 132.8, 134.6, 135.8, 136.5, 136.7, 137.0, 141.3, 148.3, 156.3, 157.5, 159.6, and 160.0; $v_{\max }$ / $\mathrm{cm}^{-1} 3330(\mathrm{NH}), 1534$ and $1324\left(\mathrm{NO}_{2}\right) ; \lambda_{\max }\left(\mathrm{CH}_{2} \mathrm{Cl}_{2}\right) \mathrm{nm}(\log \varepsilon) 270$ (4.28), 298 (4.25), 329 (4.50), 348 (4.32, sh), 422 (4.31), 464 (4.11), and 492 (3.97, sh). Anal. Calcd for $\mathrm{C}_{18} \mathrm{H}_{12} \mathrm{~N}_{4} \mathrm{O}_{2} \cdot 1 / 3$ AcOEt: C, 67.16; H, 4.28; N, 16.21. Found: C, 67.24; H, 4.26; N, 15.93.

3db : Dark red powders (from $\mathrm{CHCl}_{3}$-AcOEt), mp 255-256 ${ }^{\circ} \mathrm{C} ;{ }^{1} \mathrm{H}$ NMR (DMSO-d $\left.{ }_{6}\right) \delta 7.29$ (2H, like t, $J$ 9.1, H-6,6'), 7.32 (2H, t, J 7.6, H-p-Ph), 7.34 (2H, like t, $J$ 9.3, H-5,5'), 7.47 (4H, dd, $J 7.6$ and 7.3, H-m-Ph), 7.49 (2H, like t, J 10.0, H-7, 7’), 7.78 (4H, d, J 7.3, H-o-Ph), 8.04 (2H, dm, J 10.0, H-8, 8’), and $8.05\left(1 \mathrm{H}, \mathrm{dm}, J\right.$ 9.3, H-4,4') (NH was not observed); ${ }^{13} \mathrm{C}$ NMR (DMSO-d $\left.d_{6}\right) \delta 120.3,122.6,126.8$, 128.1, 128.6, 130.2, 131.1, 131.8, 131.9, 133.2, 140.1, 151.6, and 163.0; $v_{\max } / \mathrm{cm}^{-1} 3440(\mathrm{NH}) ; \lambda_{\max }$ $\left(\mathrm{CH}_{2} \mathrm{Cl}_{2}\right) \mathrm{nm}$ (log $\left.\varepsilon\right) 289$ (4.64), 369 (4.29), 404 (4.08, sh), 468 (4.09, sh), 498 (4.19), 568 (4.40), 603 (4.41), and 650 (4.06, sh). Anal. Calcd for $\mathrm{C}_{30} \mathrm{H}_{21} \mathrm{~N}_{3}$ : C, 85.08; H, 5.00; N, 9.92. Found: C, 85.12; $\mathrm{H}$, 5.13; N, 9.74.

\section{Reaction of 2-chloro-1-azaazulenes with 2-mercapto-1-azaazulenes}

Typical procedure A: Under argon atmosphere, a mixture of $\mathbf{1 b}(0.055 \mathrm{~g}, 0.233 \mathrm{mmol}), \mathbf{4 a}(0.036 \mathrm{~g}$, $0.223 \mathrm{mmol}$ ), Xantphos (0.0088 g, $0.015 \mathrm{mmol}), \mathrm{Pd}_{2}(\mathrm{dba})_{3}(0.0146 \mathrm{~g}, 0.016 \mathrm{mmol}), \mathrm{Cs}_{2} \mathrm{CO}_{3}(0.101 \mathrm{~g}$, $0.310 \mathrm{mmol})$ in dry 1,4-dioxane $(6 \mathrm{~mL})$ was refluxed for $24 \mathrm{~h}$ under stirring, then water $(80 \mathrm{~mL})$ was added. The mixture was extracted with $\mathrm{CHCl}_{3}$. The extract was dried over $\mathrm{Na}_{2} \mathrm{SO}_{4}$, and evaporated. Chromatography of the residue with AcOEt gave 5 ba (0.040 g, 50\%).

In a similar manner, reaction of $\mathbf{1 c}$ with 4 a gave 5 ca (38\%).

5ba : Reddish brown micro needles (from $\mathrm{CH}_{2} \mathrm{Cl}_{2}$-hexane), mp $119{ }^{\circ} \mathrm{C}$ (decomp.); ${ }^{1} \mathrm{H} \mathrm{NMR} \delta 1.54$ (3H, t, $J$ 7.1, $\mathrm{CH}_{3}$ ), 4.53 (2H, q, $J$ 7.1, $\mathrm{OCH}_{2}$ ), 7.62 (1H, like t, $J$ 9.7, H-7’), 7.72 (1H, like t, $J$ 10.2, H-5'), 7.79 (1H, like t, $J$ 10.0, H-6'), 7.83-7.90 (3H, m, H-5,6,7), 8.48 (1H, d, $J$ 10.0, H-8'), 8.57 (1H, dm, $J$ 10.6, H-8), 8.59-8.64 (1H, m, H-4'), and 9.40-9.49 (1H, m, H-4); ${ }^{13} \mathrm{C}$ NMR $\delta 14.5,60.7,113.1,116.5,129.1$, 129.7, 132.7, 132.9, 133.9, 134.3, 134.8, 135.4, 136.7, 137.9, 146.6, 147.2, 157.0, 159.1, 164.0, and 167.3; $v_{\max } / \mathrm{cm}^{-1} 1685(\mathrm{C}=\mathrm{O})$. Anal. Calcd for $\mathrm{C}_{21} \mathrm{H}_{16} \mathrm{~N}_{2} \mathrm{O}_{2} \mathrm{~S}: \mathrm{C}, 69.98 ; \mathrm{H}, 4.47 ; \mathrm{N}, 7.77$. Found: C, 70.07; H, 4.32; N, 7.83.

5ca : Red micro needles (from $\mathrm{CH}_{2} \mathrm{Cl}_{2}$-hexane), mp $216{ }^{\circ} \mathrm{C}$ (decomp.); ${ }^{1} \mathrm{H}$ NMR $\delta 7.72$ (1H, like t, $J$ 9.7, H-5’), 7.82 (1H, like t, J 9.3, H-6’), 7.90 (like t, J 9.8, H-7’), 8.03-8.15 (3H, m, H-5,6,7), 8.60 (1H, d, $J$ 9.8, H-4'), 8.68 (1H, dm, J 9.6, H-8'), 8.69 (1H, dm, J 9.8, H-8), and 9.65 (1H, dm, J 9.6, H-4); ${ }^{13} \mathrm{C}$ NMR $\delta 117.5,123.3,129.3,129.9,134.7,135.1$, 135.2, 135.8, 135.9, 136.4, 137.8, 138.1, 139.8, 140.5, 145.0, 146.8, 157.2, and 163.5; $v_{\max } / \mathrm{cm}^{-1} 1481,1394\left(\mathrm{NO}_{2}\right)$. Anal. Calcd for $\mathrm{C}_{18} \mathrm{H}_{11} \mathrm{~N}_{3} \mathrm{O}_{2} \mathrm{~S}: \mathrm{C}, 64.85 ; \mathrm{H}$, 3.33; N, 12.60. Found: C, 65.02; H, 3.32; N, 12.81 . 
Typical procedure B: A mixture of $4 \mathrm{a}(0.151 \mathrm{~g}, 0.936 \mathrm{mmol})$ and $60 \% \mathrm{NaH}(0.047 \mathrm{~g}, 1.17 \mathrm{mmol})$ in dioxane $(10 \mathrm{~mL})$ was stirred for $30 \mathrm{~min}$ at rt. Then $1 \mathrm{a}(0.212 \mathrm{~g}, 1.23 \mathrm{mmol})$ was added to the mixture, and the mixture was refluxed for $4 \mathrm{~h}$ then water $(20 \mathrm{~mL})$ was added. The mixture was extracted with $\mathrm{CHCl}_{3}$. The extract was dried over $\mathrm{Na}_{2} \mathrm{SO}_{4}$, and evaporated. Chromatography on alumina of the residue with $\mathrm{CHCl}_{3}$-AcOEt $(1: 1)$ gave 5 aa $(0.240 \mathrm{~g}$, 88\%).

In a similar manner, reaction of $\mathbf{1 b}$ and $\mathbf{1 c}$ with $\mathbf{4 a}$ and $\mathbf{4 b}$ gave $5 \mathbf{b a}(71 \%)$, 5ca (80\%), and $\mathbf{5 c b}(85 \%)$, respectively.

5aa : Red micro needles (from $\mathrm{CH}_{2} \mathrm{Cl}_{2}$-hexane), mp 217-219 ${ }^{\circ} \mathrm{C} ;{ }^{1} \mathrm{H}$ NMR $\left(\mathrm{CDCl}_{3}\right) \delta 7.78(2 \mathrm{H}, \mathrm{s}$, H-3,3'), 7.63 (dd, 2H, ddd, $J$ 10.2, 9.9, and 1.3, H-7,7'), 7.76 (2H, ddd, $J$ 10.2, 9.9, and 1.0, H-6,6'), 7.81 (2H, ddd, $J$ 10.2, 9.9, and 1.0, H-5,5'), 8.41 (2H, d, $J$ 9.9, H-4,4'), and 8.58 (2H, dd, $J 10.1$ and 1.3, H-8,8'); ${ }^{13}$ C NMR $\delta 114.5,129.4,130.0,133.4,134.0,136.6,146.8,157.8$, and 164.4. Anal. Calcd for $\mathrm{C}_{18} \mathrm{H}_{12} \mathrm{~N}_{2} \mathrm{~S}$ : C, 74.97; H, 4.19; N, 9.71. Found: C, 74.75; H, 4.32; N, 9.84.

5cb : Yellow micro needles (from $\mathrm{CH}_{2} \mathrm{Cl}_{2}$-hexane), mp 203-204 ${ }^{\circ} \mathrm{C} ;{ }^{1} \mathrm{H}$ NMR $\delta 7.99-8.06(1 \mathrm{H}, \mathrm{m}, \mathrm{H}-5)$, 8.08-8.13 (2H, m, H-5’,7’), 8.17-8.22 (3H, m, H-5), 8.63 (1H, d, J 9.5, H-8), 8.87-8.94 (2H, m, H-4’,8’), and 9.61-9.68 (1H, m, H-4); ${ }^{13} \mathrm{C}$ NMR $\delta 134.1,134.7,134.8,135.0,135.3,135.4,135.7,138.3,139.1$, 139.3, 140.4, 157.6, 163.1, and 164.1; $v_{\max } / \mathrm{cm}^{-1}$ 1485, $1304\left(\mathrm{NO}_{2}\right) ; \lambda_{\max } \mathrm{nm}(\log \varepsilon) 253$ (4.55), 286 (4.32), 335 (4.37), 351 (4.37), 387 (4.28), and 465 (2.89, sh). Anal. Calcd for $\mathrm{C}_{17} \mathrm{H}_{10} \mathrm{~N}_{4} \mathrm{O}_{2} \mathrm{~S}$ : C, 61.07; H, 3.01; N, 16.76. Found: C, 61.26; H, 3.07; N, 16.52.

\section{Reaction of ethyl 2-chloro-1-azaazulene-3-carboxylate with 4-amino-3-mercapto-4H-1,2,4-triazoles}

Typical procedure: A mixture of $\mathbf{1 b}$ (0.059 g, 0.25 mmol), 4-amino-3-mercapto-4H-1,2,4-triazole (6a) (0.059 g, $0.51 \mathrm{mmol})$ in $\mathrm{BuOH}(5 \mathrm{~mL})$ was refluxed for $30 \mathrm{~min}$. To the mixture hexane was added, and the trituration of the mixture gave yellow solid. The solid was collected by filtration and washed with $\mathrm{Et}_{2} \mathrm{O}$ to give $7 \mathrm{a}(0.073 \mathrm{~g}, 92 \%)$ as yellow powders.

In a similar manner, reaction of $\mathbf{1 b}$ with $\mathbf{6 b}$ and $\mathbf{6 c}$ gave $\mathbf{7 b}(98 \%)$ and $\mathbf{7 c}(43 \%)$, respectively.

7a: Yellow powders (from $\mathrm{CH}_{2} \mathrm{Cl}_{2}$-hexane), mp $169{ }^{\circ} \mathrm{C}$ (decomp.); ${ }^{1} \mathrm{H}$ NMR (DMSO-d $\left.d_{6}\right) \delta 1.41$ (3H, t, $J$ 7.1, Me), 4.46 (2H, q, J 7.1, $\mathrm{OCH}_{2}$ ), 8.03-8.13 (3H, m, H-5,6,7), 8.32-8.40 (1H, m, H-8), 8.81 (1H, s, H-5’), 9.19 (1H, dm, J 9.9, H-4), 10.58 (1H, br s, NH), and $13.99(1 \mathrm{H}, \mathrm{s}, \mathrm{SH}) ; v_{\max } / \mathrm{cm}^{-1} 3292(\mathrm{NH})$, $1673(\mathrm{C}=\mathrm{O})$; $\lambda_{\max }(\mathrm{DMSO}) \mathrm{nm}(\log \varepsilon) 290$ (4.66), 361 (3.85), and 435 (3.65). Anal. Calcd for $\mathrm{C}_{14} \mathrm{H}_{13} \mathrm{~N}_{5} \mathrm{O}_{2} \mathrm{~S} \cdot \mathrm{H}_{2} \mathrm{O}$ : C, 50.44; H, 4.54; N, 21.01. Found: C, 50.15; H, 4.46; N, 21.30.

7b: Yellow powders (from $\mathrm{CH}_{2} \mathrm{Cl}_{2}$-hexane), mp $217{ }^{\circ} \mathrm{C}$ (decomp.); ${ }^{1} \mathrm{H}$ NMR (DMSO-d $\left.d_{6}\right) \delta 1.43$ (3H, t, $J$ 7.1, Me), 2.43 (3H, s, Me), 4.47 (2H, q, J 7.1, $\mathrm{OCH}_{2}$ ), 8.05-8.12 (3H, m, H-5,6,7), 8.34-8.38 (1H, m, H-8), 9.19 (1H, dm, J 9.8, H-4), $10.48(1 \mathrm{H}, \mathrm{br} \mathrm{s}, \mathrm{NH})$, and $14.86(1 \mathrm{H}, \mathrm{s}, \mathrm{SH}) ; v_{\max } / \mathrm{cm}^{-1} 3270(\mathrm{NH})$, $1701(\mathrm{C}=\mathrm{O}) ; \lambda_{\max }(\mathrm{EtOH}) \mathrm{nm}(\log \varepsilon) 243$ (4.32), 260 (4.27), 290 (4.58), 354 (3.85), and 427 (3.33). 
Anal. Calcd for $\mathrm{C}_{15} \mathrm{H}_{15} \mathrm{~N}_{5} \mathrm{O}_{2} \mathrm{~S} \cdot 2 \mathrm{H}_{2} \mathrm{O}$ : C, 49.31; H, 5.24; N, 19.17. Found: C, 49.29; H, 4.49; N, 19.43. 7c: Yellow powders (from $\mathrm{CH}_{2} \mathrm{Cl}_{2}$-hexane), mp $215{ }^{\circ} \mathrm{C}$ (decomp.); ${ }^{1} \mathrm{H}$ NMR $\delta 1.40$ (3H, t, $J$ 7.1, Me), 4.42 (2H, q, $J$ 7.1, $\mathrm{OCH}_{2}$ ), 7.92-8.08 (3H, m, H-5,6,7), 8.25-8.30 (1H, m, H-8), 9.12 (1H, dm, $J$ 10.2, $\mathrm{H}-4), 14.54(1 \mathrm{H}, \mathrm{s}, \mathrm{NH})$, and $14.86(1 \mathrm{H}, \mathrm{s}, \mathrm{SH}) ; v_{\max } / \mathrm{cm}^{-1} 3286(\mathrm{NH}), 1701(\mathrm{C}=\mathrm{O}) ; \lambda_{\max }(\mathrm{DMSO}) \mathrm{nm}$ ( $\log \varepsilon$ ) 297 (4.66), 357 (3.94), and 430 (3.53). Anal. Calcd for $\mathrm{C}_{15} \mathrm{H}_{12} \mathrm{~N}_{5} \mathrm{O}_{2} \mathrm{~F}_{3} \mathrm{~S}$ : C, 47.00; $\mathrm{H}, 3.16$; N, 18.27. Found: C, 47.19; H, 3.29; N, 18.10.

\section{Reaction of ethyl 2-chloro-1-azaazulene-3-carboxylate with 4-amino-3-mercapto-4H-1,2,4-triazoles in the presence of base}

Typical procedure A: A mixture of $6 \mathrm{a}(0.1016 \mathrm{~g}, 0.875 \mathrm{mmol})$ and $60 \% \mathrm{NaH}(0.07 \mathrm{~g}, 1.75 \mathrm{mmol})$ in dioxane (8 mL) was stirred for $30 \mathrm{~min}$ at rt. Then 1a $(0.212 \mathrm{~g}, 1.23 \mathrm{mmol})$ was added to the mixture, and the mixture was refluxed for $10 \mathrm{~h}$, then water $(20 \mathrm{~mL})$ was added. The mixture was extracted with $\mathrm{CHCl}_{3}$. The extract was dried over $\mathrm{Na}_{2} \mathrm{SO}_{4}$, and evaporated. The mixture was evaporated and the residue was chromatographed with AcOEt to give $\mathbf{1 b}(0.0051$ g, 5\%) and $\mathbf{8 a}(0.1307$ g, 91\%).

In a similar manner, reaction of $\mathbf{1 b}$ with $\mathbf{6 b}$ gave $\mathbf{8 b}(85 \%)$.

8a: Yellow needles (from $\mathrm{CH}_{2} \mathrm{Cl}_{2}$-hexane), mp $173{ }^{\circ} \mathrm{C}$ (decomp); ${ }^{1} \mathrm{H}$ NMR $\delta 1.43$ (3H, t, $J$ 7.1, Me), 2.43 (3H, s, Me), 4.47 (2H, q, J 7.1, $\mathrm{OCH}_{2}$ ), 5.45 (2H, s, NH 2 ), 7.92 (1H, ddd, $J$ 10.1, 9.7, and 1.2, H-5), 7.96 (1H, ddd, J 10.1, 9.4, and 1.3, H-6), 8.01 (1H, ddd, J 9.8, 9.4, and 1.3, H-7), 8.47 (1H, d, J 9.8, H-8), $8.53\left(1 \mathrm{H}, \mathrm{s}, \mathrm{H}-5\right.$ '), and 9.47 (1H, dd, $J 9.7$ and 1.3, H-4); ${ }^{13} \mathrm{C}$ NMR (DMSO-d $\left.d_{6}\right) \delta 14.5,61.1,112.3,133.3$, 133.7, 135.8, 136.2, 139.1, 147.1, 147.3, 147.6, 158.9, 163.7, and 166.5; $v_{\max } / \mathrm{cm}^{-1} 3251,3156(\mathrm{NH})$, $1698(\mathrm{C}=\mathrm{O}) ; \lambda_{\max }\left(\mathrm{CH}_{2} \mathrm{Cl}_{2}\right) \mathrm{nm}(\log \varepsilon) 250$ (4.26), 298 (4.57), 355 (4.03), 450 (3.19). Anal. Calcd for $\mathrm{C}_{19} \mathrm{H}_{15} \mathrm{~N}_{3} \mathrm{O}_{2} \mathrm{~S} \cdot \mathrm{H}_{2} \mathrm{O}$ : C, 50.44; H, 4.54; N, 21.01. Found: C, 50.18; H, 4.49; N, 21.22.

8b: Yellow powders (from $\mathrm{CH}_{2} \mathrm{Cl}_{2}$-hexane), mp $225{ }^{\circ} \mathrm{C}$ (decomp.); ${ }^{1} \mathrm{H}$ NMR $\delta 1.54$ (3H, t, $J$ 7.1, Me), 2.62 (3H, s, Me), 4.54 (2H, q, J 7.1, $\left.\mathrm{OCH}_{2}\right), 5.29$ (2H, br s, $\left.\mathrm{NH}_{2}\right), 7.91$ (1H, ddd, $J$ 10.2, 9.7, and 1.3, H-5), 7.95 (1H, ddd, $J$ 10.2, 9.3, and 1.4, H-6), 8.01 (1H, ddd, $J$ 9.8, 9.3, and 1.4, H-7), 8.47 (1H, d, $J$ 9.8, $\mathrm{H}-8)$, and $9.46\left(1 \mathrm{H}\right.$, dd, $J 9.7$ and 1.4, H-4); $\nu_{\max } / \mathrm{cm}^{-1}$ 3247, $3147(\mathrm{NH}), 1699(\mathrm{C}=\mathrm{O}) ; \lambda_{\max }\left(\mathrm{CH}_{2} \mathrm{Cl}_{2}\right) \mathrm{nm}$ (log $\varepsilon) 251$ (4.59), 299 (4.51), 312 (4.31, sh), 357 (4.00), and 453 (3.18). Anal. Calcd for $\mathrm{C}_{15} \mathrm{H}_{15} \mathrm{~N}_{5} \mathrm{O}_{2} \mathrm{~S} \cdot 2 \mathrm{H}_{2} \mathrm{O}$ : C, 49.17; H, 5.50; N, 19.11. Found: C, 49.41; H, 5.35; N, 19.03.

Typical procedure B: A mixture of $6 \mathbf{6 a}(0.060 \mathrm{~g}, 0.52 \mathrm{mmol}), \mathrm{K}_{2} \mathrm{CO}_{3}(0.059 \mathrm{~g}, 0.43 \mathrm{mmol})$, and 18-crown-6 (0.229 g, $0.87 \mathrm{mmol})$ in dioxane $(5 \mathrm{~mL})$ was stirred for $30 \mathrm{~min}$ at rt. Then $\mathbf{1 b}(0.061 \mathrm{~g}, 0.26$ mmol) was added to the mixture, and the mixture was refluxed for $1 \mathrm{~h}$. The mixture was evaporated and the residue was chromatographed with AcOEt to give $\mathbf{8 a}(0.074 \mathrm{mg}, 92 \%)$ as yellow powders.

In a similar manner, reaction of $\mathbf{1 b}$ with $\mathbf{6 b}$ and $\mathbf{6 c}$ gave $\mathbf{8 b}(86 \%)$ and $\mathbf{8 c}(92 \%)$, respectively.

8c: Yellow needles (from $\mathrm{CH}_{2} \mathrm{Cl}_{2}$-hexane), mp 207-210 ${ }^{\circ} \mathrm{C} ;{ }^{1} \mathrm{H}$ NMR $\delta 1.54$ (3H, t, $J$ 7.1, Me), 4.55 (2H, 
q, $J$ 7.1, $\mathrm{OCH}_{2}$ ), 5.58 (2H, s, $\mathrm{NH}_{2}$ ), 7.95 (1H, ddd, $J$ 10.2, 9.6, and 1.2, H-5), 7.99 (1H, dddd, $J$ 10.2, 9.9, 1.4, and 0.8, H-6), 8.04 (1H, ddd, $J$ 9.9, 9.8, and 1.2, H-7), 8.49 (1H, dd, $J$ 9.8, and 0.8, H-7), and 9.48 (1H, dd, $J 9.6$ and 1.4, H-4); ${ }^{13} \mathrm{C}$ NMR $\delta 14.5,61.2,112.4,117.8$ (average of 114.6, 116.7, 118.9, and 121.0, q, J 270.9, $\underline{\mathrm{CF}}_{3}$ ), 133.6, 133.9, 136.2, 136.6, 139.6, 147.0, 147.5 (average of 147.0, 147.3, 147.6, and 147.9, q, $J$ 39.7, $\left.\underline{C C F}_{3}\right), 151.4,158.8,163.5$, and 164.1; $v_{\max } / \mathrm{cm}^{-1} 3320,3193(\mathrm{NH}), 1687$ (C=O); $\lambda_{\max }\left(\mathrm{CH}_{2} \mathrm{Cl}_{2}\right) \mathrm{nm}(\log \varepsilon) 246$ (4.29), 296 (4.63), 352 (4.05), 451 (3.21), and 476 (3.01, sh). Anal. Calcd for $\mathrm{C}_{15} \mathrm{H}_{12} \mathrm{~N}_{5} \mathrm{O}_{2} \mathrm{~F}_{3} \mathrm{~S}$ : C, 47.00; H, 3.16; N, 18.27. Found: C, 46.82; H, 3.21; N, 18.45.

\section{REFERENCES AND NOTES}

1. For reviews see, N. Abe, 'Recent Research Developments in Organic and Bioorganic Chemistry'2001, 4, 14, Transworld Research Network; T. Nishiwaki and N. Abe, Heterocycles, 1981, 15, 547; M. Kimura, Yuki Gosei Kagaku Kyokai Shi, 1981, 39, 690.

2. T. Ishikawa and A. Zeimoto, Jpn. Kokai Tokkyo Koho, JP 1999, 11,255,746.

3. M. Nagahara, J. Nakano, M. Miura, T. Nakamura, and K. Uchida, Chem. Pharm. Bull., 1994, 42, 2491.

4. D. Lednicer, Strategies for Organic Drug Synthesis and Design; John Wiley and Sons, New York, 1998.

5. S. Tasler, J. Mies, and M. Lang, Adv. Synth. Catal., 2007, 349, 2286.

6. R. Jiang, D. Duckett, W. Chen, J. Habel, Y. Y. Ling, P. Lograsso, and T. M. Kamenecka, Bioorg. Med. Chem. Lett., 2007, 17, 6378.

7. W. Huang, W. Zheng, D. J. Urban, J. Inglese, E. Sidransky, C. P. Austin, and C. J. Thomas, Bioorg. Med. Chem. Lett., 2007, 17, 5783.

8. P. Ballard, B. C. Barlaam, R. H. Bradbury, A. Dishington, L. F. A. Hennequin, D. M. Hickinson, I. M. Hollingsworth, J. G. Kettle, T. Klinowska, D. J. Oglivie, S. E. Pearson, J. S. Scott, A. Suleman, R. Whittaker, E. J. Williams, R. Wood, and L. Wright, Bioorg. Med. Chem. Lett., 2007, 17, 6326.

9. For the reviews on the Pd-catalyzed amination reactions, see (a) J. F. Hartwig, Angew. Chem., Int. Ed., 1998, 37, 2046; (b) J. P. Wolfe, S. Wagaw, J.-F. Marcoux, and S. L. Buchwald, Acc. Chem. Res., 1998, 31, 805; (c) B. H. Yang and S. L. Buchwald, J. Organometal. Chem., 1999, 576, 125; D. Prim, J.-M. Campagne, D. Joseph, and B. Andrioletti, Tetrahedron, 2002, 58, 2041.

10. K. Koizumi, K. Shimabara, A. Takemoto, S. Yamazaki, N. Yamauchi, H. Fujii, M. Kurosawa, T. Konakahara, and N. Abe, Heterocycles, 2009, 79, 319. 